\title{
Challenges and Opportunities Facing China's Urban Development in the New Era
}

\section{Han Ruibo and Wang Linna}

\section{(2) OpenEdition \\ 1 Journals}

\section{Electronic version}

URL: http://journals.openedition.org/chinaperspectives/6149

DOI: 10.4000/chinaperspectives.6149

ISSN: 1996-4617

\section{Publisher}

Centre d'étude français sur la Chine contemporaine

\section{Printed version}

Date of publication: 1 June 2013

Number of pages: 15-27

ISSN: 2070-3449

\section{Electronic reference}

Han Ruibo and Wang Linna, « Challenges and Opportunities Facing China's Urban Development in the New Era », China Perspectives [Online], 2013/2 | 2013, Online since 01 June 2016, connection on 10 December 2020. URL : http://journals.openedition.org/chinaperspectives/6149; DOI : https://doi.org/ 10.4000/chinaperspectives.6149 


\title{
Challenges and Opportunities
}

\section{Facing China's Urban Development}

\section{in the New Era}

\author{
A statistical and spatial analysis
}

HAN RUIBO, WANG LINNA

\begin{abstract}
The acceleration of urban expansion has greatly impacted the study of China's urban system, as the urban function at the national level has largely been characterised by the spatial distribution and evolution of cities. In order to understand the dynamics of urban development in China, it is necessary to analyse the history of city evolution and understand the context in which that evolution took place. The first section of this paper introduces the urbanisation process in China since the 1950s in order to demonstrate the origins of China's recent urbanisation patterns. Subsequently, the structural transitions of city scaling and urban clusters are presented by employing Rank-size Analysis and satellite imagery, followed by the challenges brought about by these changes. Finally, the spatial distribution and transition patterns of China's urban system are analysed using Centrographic Analysis.
\end{abstract}

KEYWORDS: Chinese urban system, urbanisation patterns, institutional transition, structural transition, spatial transition.

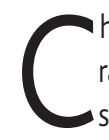
hina's urbanisation in the last few decades has been occurring at a rapid rate that is unmatched by any other country. Although China surpassed the United States to become the country with the largest urban population in terms of absolute numbers during the mid-1970s (Graph 1.A), its urbanisation rate was barely $18 \%$ at the time. It was not until the introduction of the open door policy and economic reforms in the early 1980s that China experienced exponential economic growth and subsequent rapid urbanisation (Graph 1.B). According to the first report released by the 2010 National Census Office, 670 million people (roughly $50 \%$ of the population) are living in cities and towns, a $13.46 \%$ increase from the number released in the 2000 census. ${ }^{(1)}$ As indicated in Graph 1.B, China faces consistently rapid urbanisation in the long-term: another $20 \%$ of the Chinese population is going to be urbanised, and China's urbanisation rate will reach $70 \%$ between 2035 and 2045. (2) Despite the fact that China's urbanisation rate has only recently reached the worldwide average of $50 \%,{ }^{(3)}$ the speed of China's urbanisation is unprecedented given its large population size; its cities are continuously expanding in terms of their number and spatial scale. ${ }^{(4)}$

The astonishing pace of China's urban growth presents various concerns. It is crucial that China's government and policy-makers pause to consider emerging issues regarding the current state of China's urbanisation as they continue pursuing rapid development. In order to make urban growth sustainable in the future, China must assess its urbanisation path and ask some important questions: How have political and economic systems been influencing urban growth? What patterns have been generated as a result of the economic reforms and subsequent growth? Has development been evenly distributed, both spatially and temporally? What measures should be taken to pursue sustainable development at such a high speed? This paper will attempt to address these questions.

By analysing the historical evolution of cities in China, and the context under which it took place, the unique dynamics of urban development in China can be understood. The first section of this paper introduces China's urbanisation process since the 1950s in order to reveal the origins of the country's modern urbanisation patterns. This is followed by a discussion of institutional barriers that impeded its urban development. Subsequently, the structural transitions of city scaling and urban clusters are studied by employing Rank-size Analysis and satellite imagery, including an analysis of the challenges that accompany these changes. After reviewing these challenges, the spatial distribution and transition patterns of China's urban system are analysed using Centrographic Analysis. This paper endeavours to conduct a systematic analysis of the Chinese urban system that not only provides a better understanding of the current urban landscape, but also has far-reaching implications for conceptualising, understanding, and planning future urban development in China.

China's political and economic regimes have experienced a complicated development process since the establishment of the People's Republic of

1. National Bureau of Statistics of China, "Major Figures of the Sixth National Population Census, 2010," National Bureau of Statistics of China, Beijing, 2011

2. United Nations, "World urbanisation prospects: The 2005 revision," 2005; United Nations, "World urbanisation prospects: The 2007 revision," 2007.

3. National Bureau of Statistics of China, "Major Figures of the Sixth National Population Census, 2010," National Bureau of Statistics of China, Beijing, 2011.

4. Clifton W. Pannell, "China's Continuing Urban Transition," Environment and Planning A, Vol. 34, 2002, pp. 1571-1589; and Clifton W. Pannell, "China's Demographic and Urban Trends for the 21st Century," Eurasian Geography and Economics, Vol. 44, No. 7, 2003, pp. 479-496. 

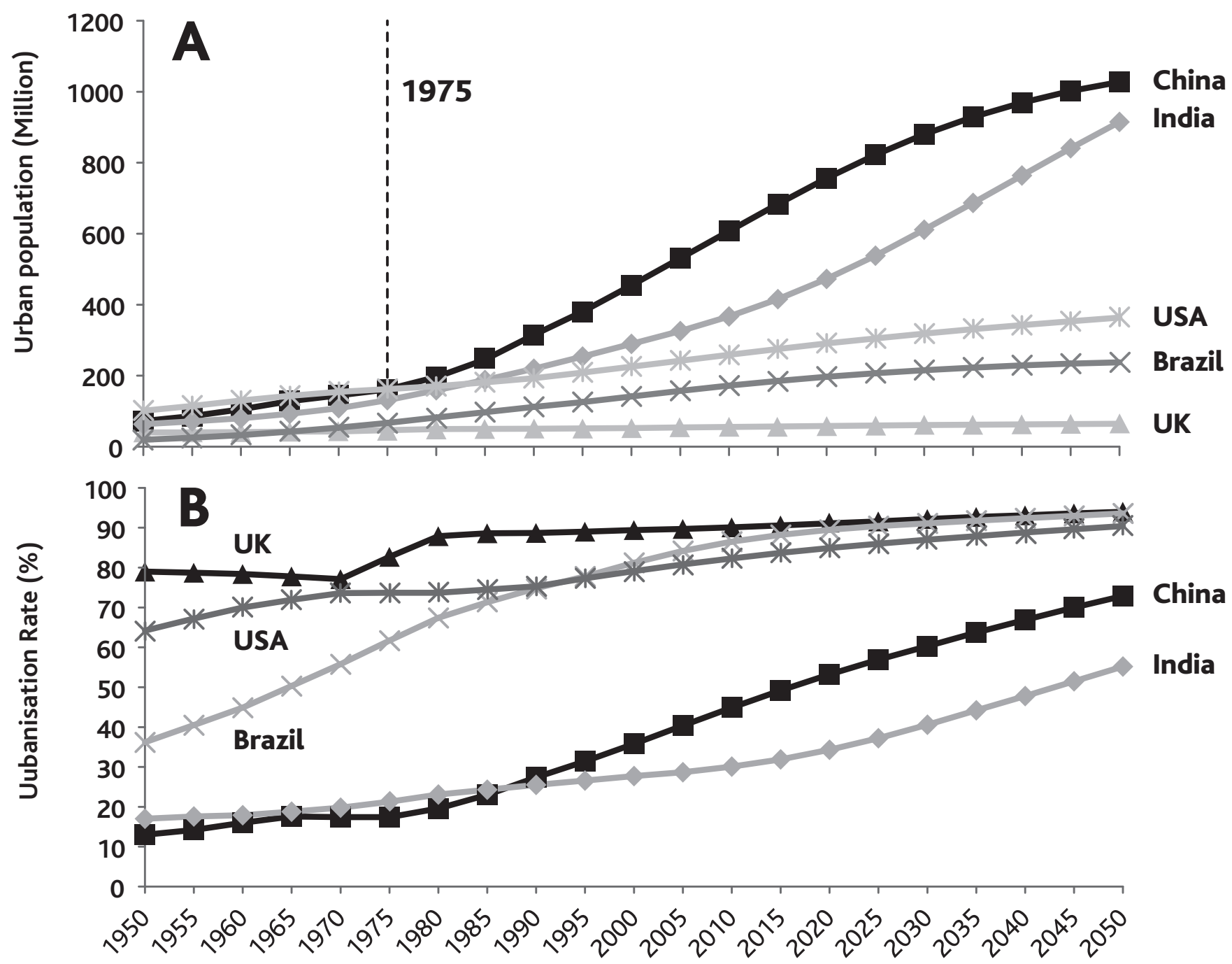

Data source:World Population Prospects, The 2006 Revision and 2007 Revision, www.esa.un.org/unup

China (PRC) in 1949. Various studies have been conducted attempting to delineate the stages of urbanisation in China, (5) but the fact remains that cities in China have undergone distinct phases of expansion, contraction, stagnation, and explosion over the past six decades. Based on the variation in the number and population of cities, the contemporary history of China's urbanisation since 1949 is divided into three stages in this study (Graph 2): Pre-reform (1949-1978), Revival (1979-1996), and Transition (1996-present). In order to present a comprehensive view of China's urban development, this process is discussed from institutional, structural, and spatial perspectives.

\section{Institutional Transition}

\section{Pre-reform (1949-1978)}

The Pre-reform phase consists of the "Rehabilitation period of the national economy" (1949-1952) and the First Five-Year Plan (1953-1957), during which the Chinese leadership under Mao Zedong embarked on an intensive economic reform program designed to emulate the Soviet model based on heavy industry. It was remarkably successful in terms of urban development, and the urbanisation rate grew steadily from $10.64 \%$ in 1949 to $15.39 \%$ in 1957. ${ }^{(6)}$ However, since heavy industry is not as effective as light industry in absorbing rural labour, the rate of urbanisation did not keep pace with industrialisation.

During China's three-year "Great Leap Forward" (da yuejin 大跃进) campaign (1958-1960), which followed the First Five-Year Plan, large-scale migration from the countryside to urban areas took place. Consequently the number of cities increased dramatically from 176 in 1957 to 209 in 1961. The urbanisation rate reached $19 \%$ in 1960, which was maintained until 1980. (7) However, the Great Leap Forward was unrealistic and resulted in

5. Zhuoyong Chen, "Urbanisation and Spatial Structure Evolution of Urban System in China," IDEJETRO, 2008, www.ide.go.jp/English/Publish/Download/Vrf/pdf/439.pdf (accessed on 26 March 2013); Lamia Kamal-Chaoui, Edward Leman, and Rufei Zhang, "Urban Trends and Policy in China," OECD Regional Development Working Papers, Vol. 1, 2009; and George C.S. Lin,"The Growth and Structural Change of Chinese Cities: A Contextual and Geographic Analysis," Cities, Vol. 19, No. 5, 2002, pp. 299-316; Clifton W. Pannell, "China's Continuing Urban Transition," art. cit.

6. Zhuoyong Chen, "Urbanisation and Spatial Structure Evolution of Urban System in China," op. cit.

7. George C.S. Lin, "The Growth and Structural Change of Chinese Cities: A Contextual and Geographic Analysis," art. cit. 
Graph 2 - Urban development phases of China ${ }^{(8)}$

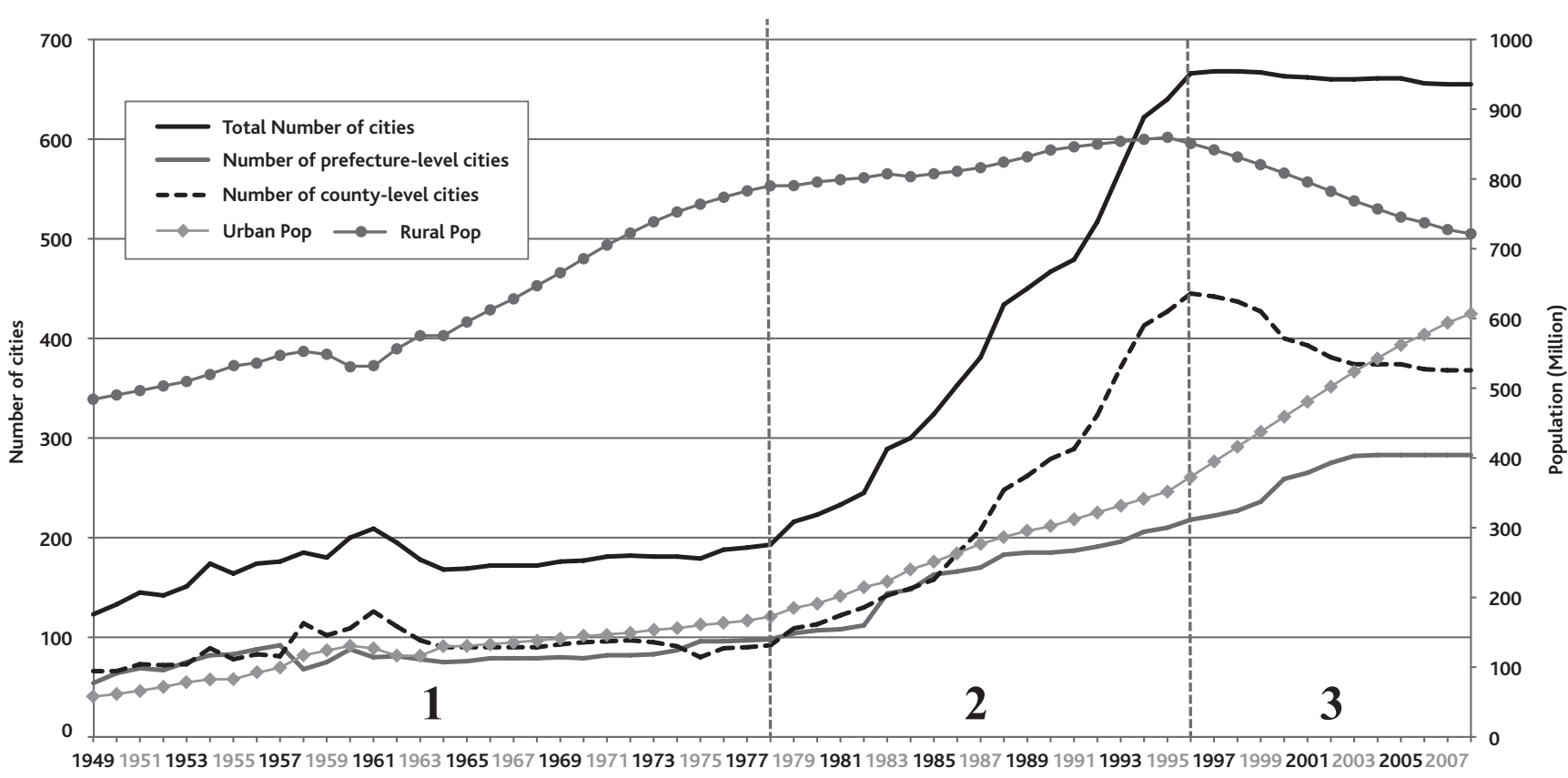

Data source: China City Statistical Yearbook 2009

catastrophe. From 1959 to 1961, China suffered a widespread famine causing millions of deaths ${ }^{(9)}$ and significantly decreasing the rural population between 1958 and 1960 (Phase 1 in Graph 2).

Due to the influx of rural labour and the proliferation of newly designated cities, the demand for financial assistance from the government to urban areas increased dramatically. The central government launched an Economic Readjustment Plan in 1962 in response to these demands. This plan entailed the elimination of some cities and the enforcement of the household registration (hukou 户口) system, resulting in a decrease in the number of cities from 209 in 1961 to 169 in 1965, and a decrease in the proportion of the urban population to $18 \%{ }^{(10)}$ By strictly controlling the population and resources, the Chinese government was able to stabilise the urbanisation rate for much of the following decade.

The Cultural Revolution (wenhua da geming 文化大革命, 1966-1976) was a period of widespread political and social upheaval that resulted in nationwide chaos and economic instability. Economic and urban development in China was frozen for over a decade (Phase 1 in Graph 2) with the exception of cities in the central and western regions, which were developed for military and national security purposes. In 1978, the introduction of an open policy and economic reform marked the end of Mao's regime and ushered in a new era of economic and urban revival.

\section{Revival phase (1979-1996)}

In 1979, Mao's pragmatic successor, Deng Xiaoping, earnestly began a process of economic reform aimed at generating sufficient surplus to finance the modernisation of the Chinese economy. The first part of this economic reform involved the introduction of a Household Responsibility System (HRS - jiating lianchan chengbao zerenzhi 家庭联产承包责任制). China's HRS, which applied to agricultural land, implemented production quotas for households that allowed them to market the surplus production of their individual plots as opposed to farming for the collective. The adop- tion of the HRS successfully motivated farmers and greatly increased productivity, but it also created a large number of surplus rural labourers. With the relaxation of restrictions prohibiting farmers from migrating to urban areas, rural labourers were encouraged to migrate to small towns in order to establish or join industries owned by townships and villages (Town and Village Enterprises, TVEs-xiangzhen qiye 乡镇企业). The subsequent growth of TVEs brought about a period of prosperity in small towns, which played an important role in urban development. In conjunction with increased flexibility in the designation of urban areas, rural development and reforms provided impetus for the upgrading of towns into cities and the expansion of small cities. ${ }^{(11)}$ From 1978 to 1996, the number of cities in China more than tripled from 193 to 666 . County-level cities were the primary drivers of this astounding urban growth, compared to their prefecture-level counterparts (Phase 2 in Graph 2). According to Table 1, the population residing in small urban areas (less than 0.2 million inhabitants) accounted for a mere 13\%

8. There are three administrative types of cities in China: 1) provincial-level municipalities (PLMs); 2) prefecture-level cities (PLCS); and 3) county-level cities (CLCS). In addition, administrative towns are today also considered "urban" settlements. PLMs (currently include Beijing, Shanghai, Tianjin, and Chongqing) report directly to the central government. A province is usually divided into a number of prefectures, which are administered by PLCS, and these PLCs report to provincial governments. Counties in a prefecture are subordinated to the governing PLC, and a county is centred at and administered by a town. A CLC is actually a town that meets the criteria for a statutory city. Up to 1982 , urban population referred to the total population of cities and towns. In the 1990s, urban population included (1) all residents of urban districts in provincial and prefecturallevel cities; (2) the resident population of subdistricts (jiedao) in county-level cities; (3) the population of all residents' committees in towns. Since 2000, urban population is composed of the population in City Districts with an average population density of at least 1,500 persons per square kilometre, and other populations in sub-district units and township-level units meeting criteria such as "contiguous built-up area," being the location of the local government, or being a subdistrict or having a Resident Committee.

9. Dennis Tao Yang, "China's Agricultural Crisis and Famine of 1959-1961:A Survey and Comparison to Soviet Famines," Comparative Economic Studies, Vol. 50, No. 1, 2008, pp. 1-29.

10. George C.S. Lin, "The Growth and Structural Change of Chinese Cities: A Contextual and Geographic Analysis," art. cit.

11. Mei-Ling Hsu, "The Expansion of the Chinese Urban System, 1953-1990," Urban Geography, Vol. 15, No. 6, 1994, pp. 514-536, and George C.S. Lin, "The Growth and Structural Change of Chinese Cities: A Contextual and Geographic Analysis," art. cit. 
Table 1 - The variation of the ranking scale of China's cities

\begin{tabular}{|c|c|c|c|c|c|c|c|c|c|c|c|}
\hline \multirow{2}{*}{ Year } & \multirow{2}{*}{$\begin{array}{l}\text { Total } \\
\text { number } \\
\text { of cities }\end{array}$} & \multicolumn{2}{|c|}{$\begin{array}{l}\text { Metropolitan } \\
\text { Pop } \geq 2 \text { Million }\end{array}$} & \multicolumn{2}{|c|}{$\begin{array}{c}\text { Extra-large } \\
2>\text { Pop } \geq 1 \text { Million }\end{array}$} & \multicolumn{2}{|c|}{$\begin{array}{c}\text { Large } \\
\text { 1>Pop } \geq 0.5 \text { Million }\end{array}$} & \multicolumn{2}{|c|}{$\begin{array}{c}\text { Medium } \\
0.5>\text { Pop } \geq 0.2 \text { Million }\end{array}$} & \multicolumn{2}{|c|}{$\begin{array}{c}\text { Small } \\
\text { Pop<0.2 Million }\end{array}$} \\
\hline & & $\begin{array}{l}\text { Number } \\
\text { of cities }\end{array}$ & $\begin{array}{l}\% \text { of total } \\
\text { population }\end{array}$ & $\begin{array}{l}\text { Number } \\
\text { of cities }\end{array}$ & $\begin{array}{l}\% \text { of total } \\
\text { population }\end{array}$ & $\begin{array}{l}\text { Number } \\
\text { of cities }\end{array}$ & $\begin{array}{l}\% \text { of total } \\
\text { population }\end{array}$ & $\begin{array}{l}\text { Number } \\
\text { of cities }\end{array}$ & $\begin{array}{l}\% \text { of total } \\
\text { population }\end{array}$ & $\begin{array}{l}\text { Number } \\
\text { of cities }\end{array}$ & $\begin{array}{l}\% \text { of total } \\
\text { population }\end{array}$ \\
\hline 1975 & 184 & 5 & 23.4 & 8 & 15.3 & 25 & 24.1 & 52 & 22 & 95 & 15.1 \\
\hline 1980 & 223 & 7 & 26.7 & 8 & 12.3 & 30 & 24.6 & 70 & 23.5 & 108 & 13 \\
\hline 1985 & 324 & 8 & 24.8 & 13 & 14.6 & 31 & 19.4 & 94 & 24.5 & 178 & 16.8 \\
\hline 1990 & 467 & 9 & 22.9 & 22 & 18.7 & 28 & 12.6 & 117 & 24.2 & 291 & 21.5 \\
\hline 1995 & 640 & 10 & 19.8 & 22 & 15.1 & 43 & 14.8 & 191 & 28.8 & 374 & 21.4 \\
\hline 2000 & 665 & 13 & 22.4 & 22 & 14.5 & 54 & 15.5 & 220 & 28.9 & 352 & 18.5 \\
\hline 2005 & 661 & 22 & 30.1 & 32 & 14.7 & 83 & 18.9 & 227 & 23.6 & 297 & 12.8 \\
\hline 2007 & 656 & 23 & 31.7 & 35 & 15.2 & 82 & 17.7 & 233 & 23.4 & 283 & 11.9 \\
\hline
\end{tabular}

Data source: The Compilation of 50 Years' Urban Statistics of New China; The Compilation of the Demographic Statistics of China 1949-1985; China City Statistical Yearbook 2001, 2006; China Population and Employment Statistics Yearbook 2008

\section{Map 1 - Open cities in China since 1979}

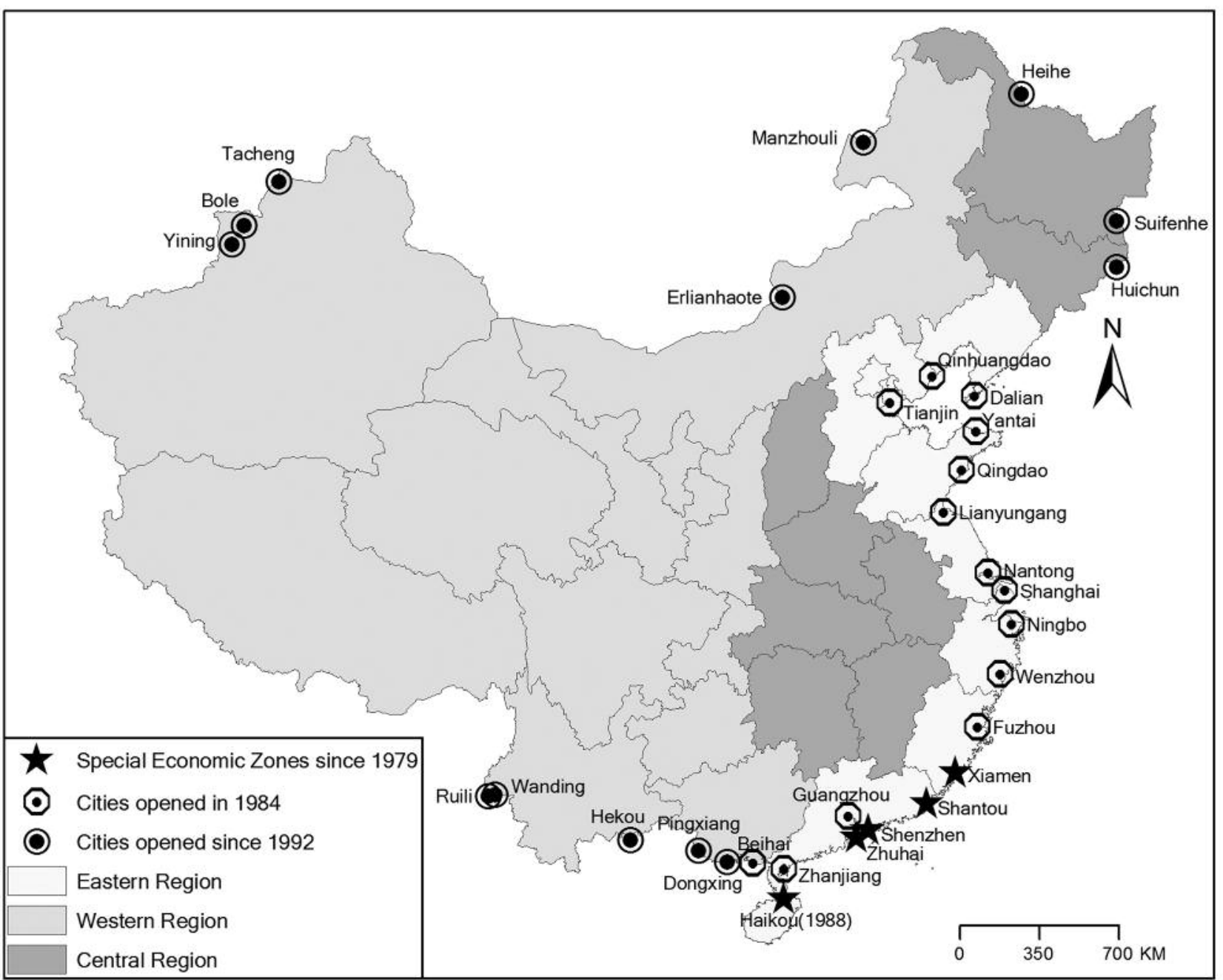

in 1980, but then soared to around $21 \%$ in the early 1990s. China's national urbanisation policy in the 1980s, which emphasised "controlling the big cities, moderating development of medium-sized cities, [and] encouraging growth of small cities," played a significant role in controlling the number and population of the country's cities ${ }^{(12)}$ (Table 1).
China's economic reforms were carried out through a series of simultaneous actions. China introduced an "Open Door" policy in the spring of 1979 that

12. Cities of China are classified based on their non-agricultural population into the following five categories: $0.1-0.2$ million for a small city, 0.2-0.5 million for a medium city, $0.5-1$ million for a large city, 1-2 million for an extra-large city, and >2 million for a metropolitan city. 


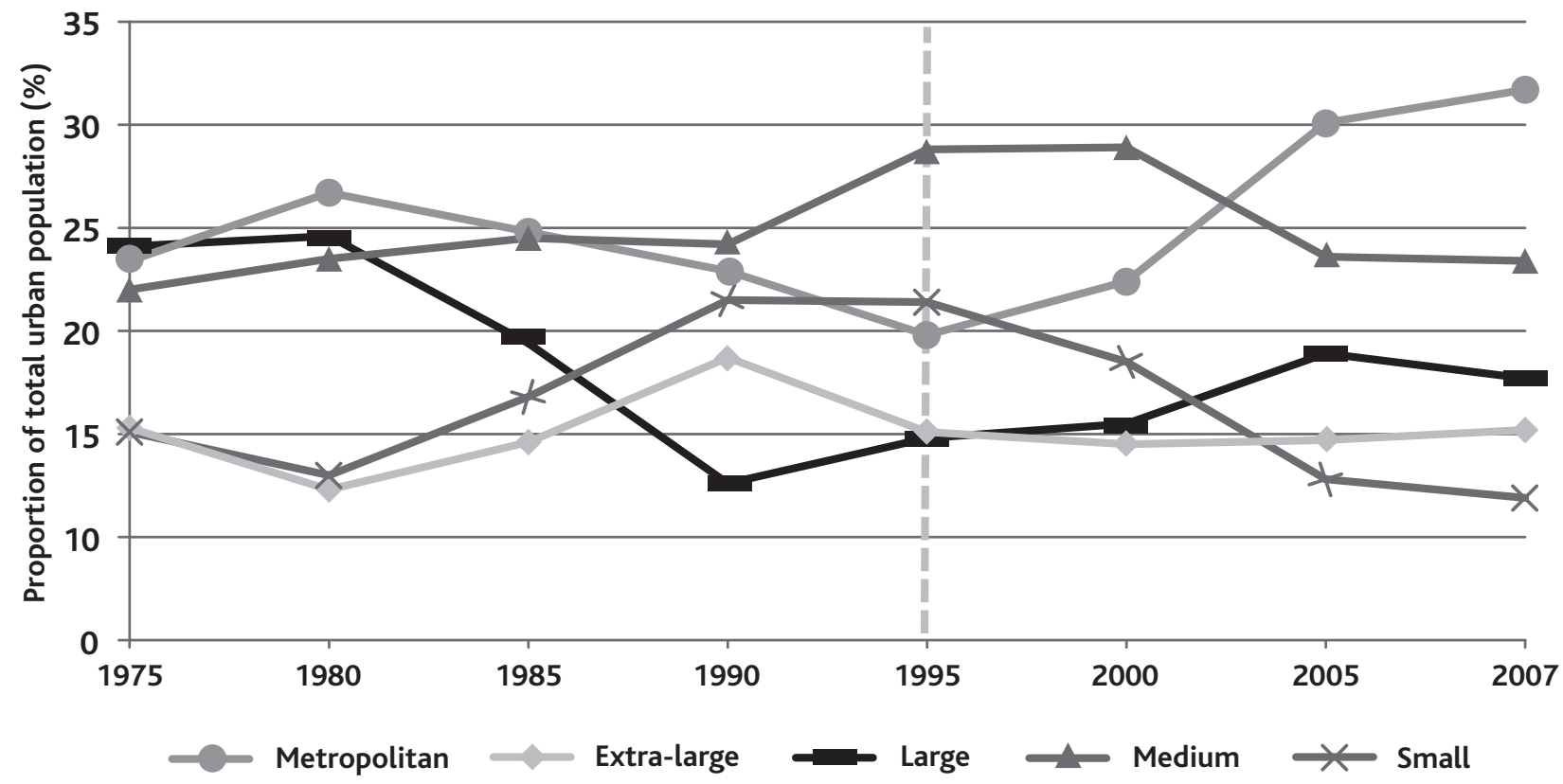

encouraged direct foreign investment and international trade to spur its economy. Recognising the economic and geographic advantages of the coastal cities, the Chinese government established four Special Economic Zones in 1979: Shenzhen, Zhuhai, Shantou, and Xiamen, with Hainan added in 1988. (13) Then, inspired by the rapid development of these zones, China designated 14 open coastal cities in 1984 and 13 open border cities in 2000 (Map 1), all of which were given the autonomy to act as experimental sites for attracting foreign investment and free markets. By the late 1980s, the Special Economic Zones policy had generated rapid development in the selected open coastal cities, triggering the first wave of renewed urban construction and urbanisation. ${ }^{(14)}$ After beginning to integrate its economy internationally, China also endeavoured to transform its economy from a centrally controlled socialist one to a market-driven one with government intervention.

In 1979, the Chinese government implemented the Birth Planning Policy, including the "One Child Policy," in an attempt to alleviate social, economic, and environmental problems. Although the One Child Policy has been controversial due to concerns over its negative social consequences, (15) it successfully curbed population growth. By managing China's population growth, the government avoided exacerbating social issues such as slum development, demand for social services (health, education, law enforcement), and ecological strains from the overexploitation of arable land and high volumes of waste. As a result of the Birth Planning Policy as well as increased rural-urban mobility, the annual growth rate of the rural population was much smaller than in previous decades, and the absolute number of rural residents plateaued in 1995 (Phase 2 in Graph 2).

With the relaxation of state control and the operation of market reforms, the period of economic revival (1978-1996) witnessed the expansion of small and medium-sized cities. At the same time, agricultural restructuring and rural industrialisation greatly increased productivity and the standard of living for most of the Chinese population, which generated support for further development.

\section{Transition phase (1996-present)}

Starting with the Ninth Five-Year Plan (1996-2000), China entered into a new transitional phase that continued with the Tenth (2001-2005) and Eleventh Five-Year Plans (2006-2010). Economic reform continued, but China's policies toward urbanisation and the configuration of the urban system have shifted from the old system of status designation to a newer, migration-based structure.

Different levels of government have played a crucial role in the development of the urban system throughout its evolution. Until recently, two of the most important factors in shaping urban growth have been politics and public policy. ${ }^{(16)}$ However, since the adoption of Opening and Reform policies at the end of the 1970s, the importance of the government's role has gradually diminished due to the relaxation in attitude towards the establishment of cities. ${ }^{(17)}$ Urban growth during the Revival Period owed much to the designation of cities at the county level (Phase 2 in Graph 2). This resulted in a massive increase in the urban population through the urban household registration system (hukou) simply because of the promotion of many towns to city status. The population residing in small cities accounted for $13 \%$ of the national urban population in 1980 , but this increased to $21 \%$ in 1995 (Table 1 and Graph 3). Essentially, the increased urbanisation of this period was propelled by the designation of new cities.

13. Huhua Cao, Ying Zhao, and Sylvain Losier, "Le projet urbain de Pudong à Shanghai offre-t-il un développement durable pour la globalisation de la Chine?" (Does the Pudong Urban Project in Shanghai Have a Sustainable Future?), Les Annales de la recherche urbaine, Vol. 86, 2000, pp. 92-100.

14. Lamia Kamal-Chaoui, Edward Leman, and Rufei Zhang, "Urban Trends and Policy in China," op. cit.

15. M. Giovanna Merli, and Adrian E. Raftery, "Are Births Underreported in Rural China? Manipulation of Statistical Records in Response to China's Population Policies," Demography, Vol. 37, No. 1, 2000, pp. 109-126.

16. Kenneth A. Small, "Chinese Urban Development: Introduction," Urban Studies, Vol. 39, No. 12, 2002, pp. 2159-2162; Shunfeng Song and Kevin Honglin Zhang, "Urbanisation and City Size Distribution in China," Urban Studies, Vol. 39, No. 12, 2002, pp. 2317-2327.

17. Anthony Gar-On Yeh and Xueqiang Xu,"Urbanisation and Urban System Development in China," in Fuchen Lo and Yueman Yeung, Emerging World Cities in Pacific Asia, Tokyo, New York, Paris, United Nations University Press, 1996 


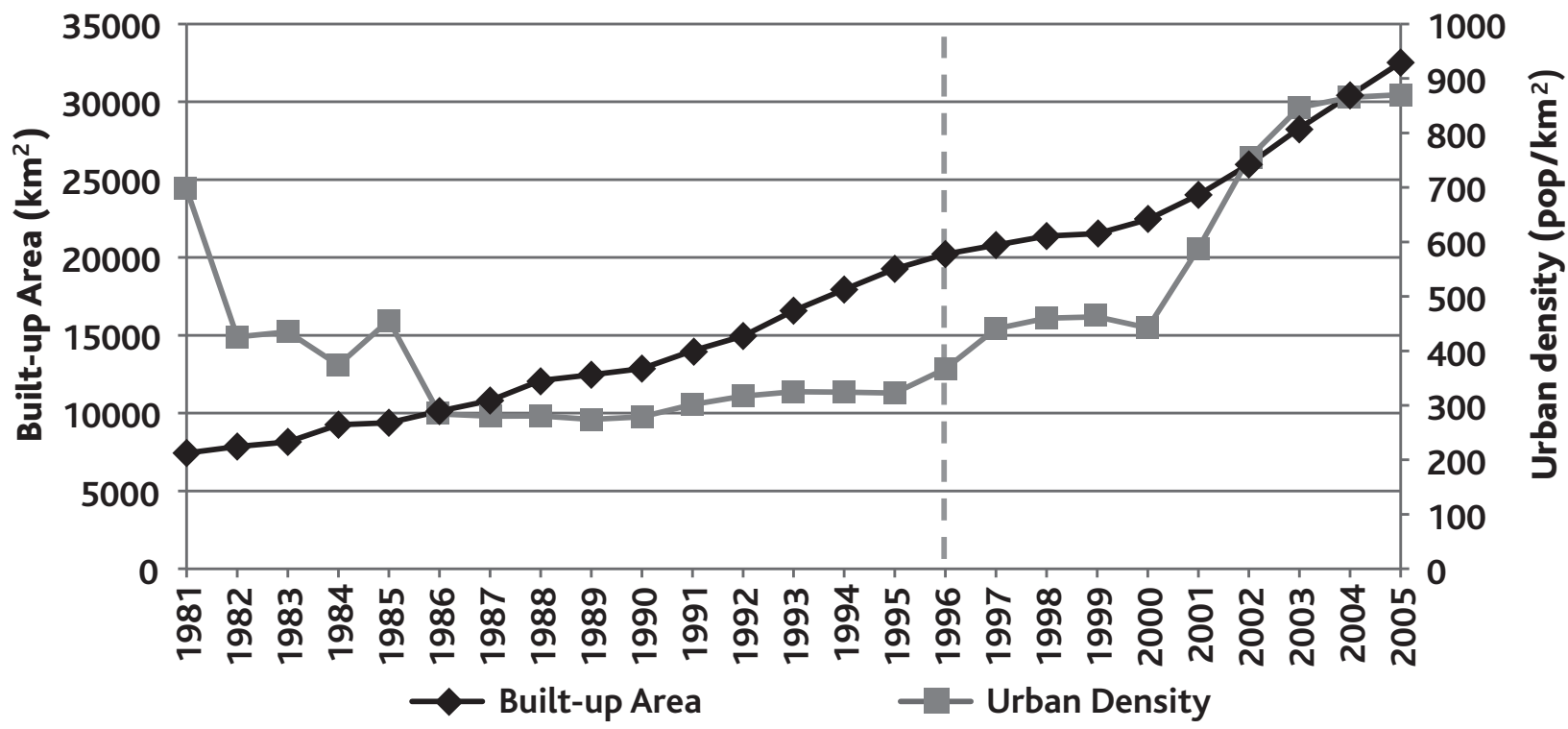

Data source: China Statistical Yearbook of Urban Construction 2007

In the mid-1990s, the Chinese government began to shift its emphasis from "encouraging the development of small cities" to "a coordinated development of large, medium, and small cities and small towns." (18) Consequently, from the late 1990s onward, policy-makers moved from designating new cities towards promoting growth through urban migration. As illustrated by Graph 2, although the urban population was growing at extraordinary speed after 1995 , the total number of cities remained stable at around 650. In a parallel phenomenon, the rural population was diminishing at a consistently rapid rate for the first time in China's history. This reduction in the rural population was mainly caused by rural-to-urban and inter-city migration rather than by the transformation of villages to towns. Given that larger cities have better access to resources and investment, which in turn creates a more vibrant job market and better facilities and infrastructure, it is unsurprising that many people left the countryside for urban areas. Consequently, the number of people residing in metropolitan areas swelled from 20\% in 1995 to 32\% in 2007 (Graph 3). The urban density also shifted dramatically due to massive urban migration, growing from 323 people per square kilometre in 1995 to 870 in 2005 (Graph 4).

\section{Urban structural transition}

As a result of the economic and urban reforms, the structure of China's urban system has also experienced a significant transition. Rank-size analysis, or the rank-size rule or Zipf's law, describes the regularity in the distribution of city sizes around the world. If the population size of cities of a country is ranked and the rank of the city population are calculated using the natural logarithm, the resulting graph should show a log-linear pattern. A Rank-size Analysis of the urban system of China reveals that smaller cities are increasing in size; however, the overall structure remains unbalanced due to the extraordinarily large number of small cities. This emergence of urban clusters provides both opportunities and challenges for urban development in this new era.

\section{Evolution of scaling distribution: upgrade of smaller cities}

Land and housing reforms in the late 1990s were two major progressions in China's economic restructuring that led to the flourishing of the land and housing markets. ${ }^{(19)}$ Due to the massive inflow of migrants, cities grew in both size and scale. During the past two decades, the development of Chinese cities has been evolving along two distinct patterns, as can be seen in the Rank-size distribution diagram of Chinese cities (Graph 5). From 1985 to 1995 , small and medium-sized cities grew substantially in size. As shown in Graph 5, the distribution of high-ranking cities converges during this period whereas the distribution of low-ranking cities remains distinct, which means that there was substantial growth in the size of smaller cities. As indicated in Table 1, the number of small and medium-sized cities more than doubled from 1985 to 1995, and the proportion of urban residents in these cities also increased from $41.3 \%$ to $50.2 \%$.

Conversely, the expansion of large cities and the upgrading of small cities dominate the statistics from 1995 to 2005. In Rank-size distribution, lowerranked cities remain clustered on the diagram during this decade, whereas higher-ranked cities shifted more, indicating an increase in the size of larger cities (Graph 5). The data shown in Table 1 reinforces the existence of this trend. From 1950 to 2005, the number of lower-ranked cities did not vary, whereas the number of higher-ranked cities nearly doubled. These higher-ranked cities include metropolitan areas, extra-large, and large cities, with the proportion of urban population living in these areas increasing by $10 \%$ in 10 years.

\section{Unbalanced structure of the urban system}

According to Table 1, small cities accounted for more than $60 \%$ of the total number of cities in China in 1995. In the same year, medium-sized

18. Lamia Kamal-Chaoui, Edward Leman, and Rufei Zhang, "Urban Trends and Policy in China," op. cit. 19. Chengri Ding, "Land Policy Reform in China: Assessment and Prospects," Land Use Policy, Vol. 20, No. 2, 2003, pp. 109-120. 


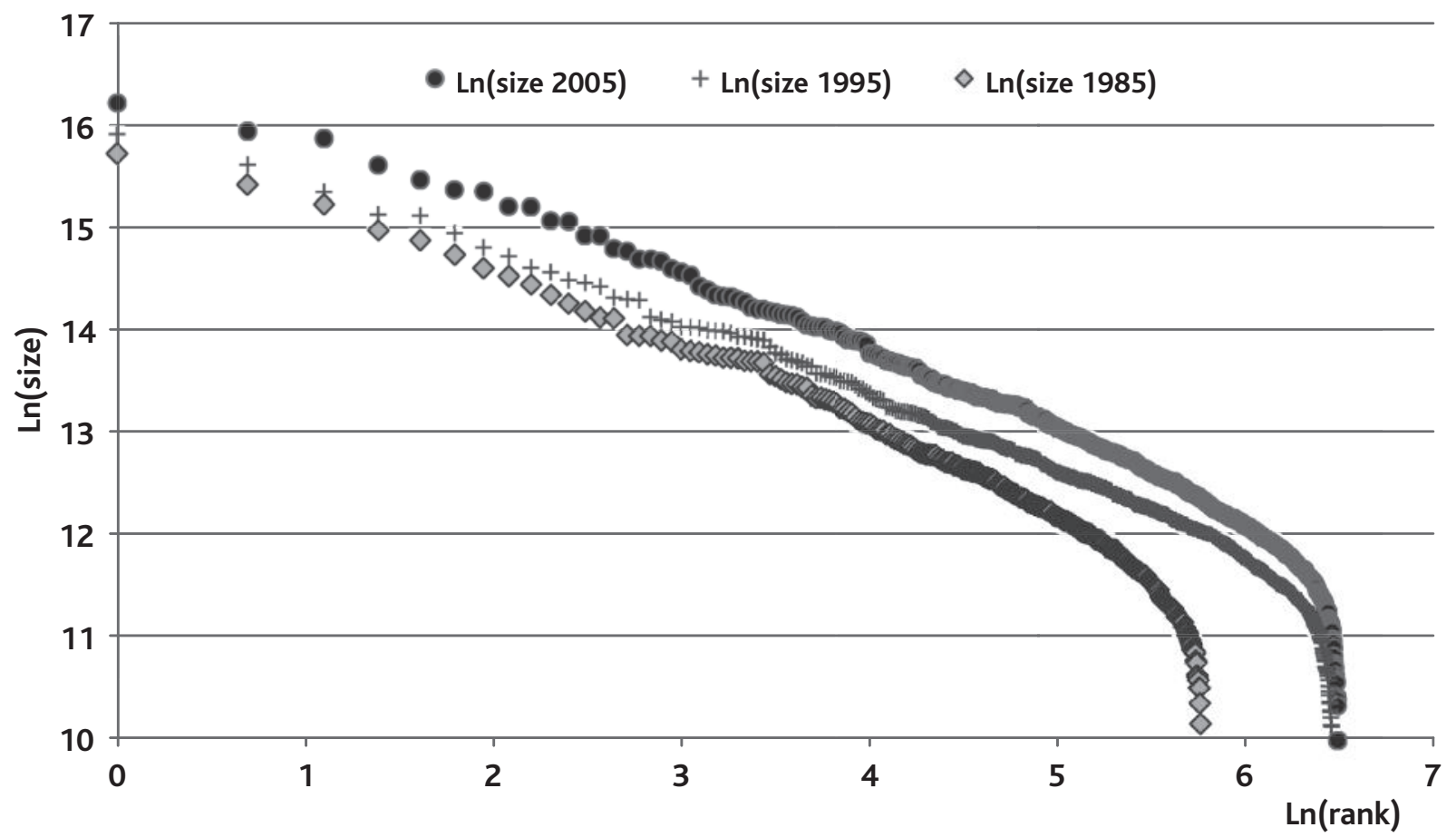

The size of cities refers to the number of non-agricultural residents, and rank starts from 1 , which is the largest city, and $\operatorname{Ln}(1)$ equals to 0 .

Source: China City Statistical Yearbook 1986, 1996 and 2006.

cities comprised another $30 \%$ of the total, leaving only $10 \%$ for larger cities. Approximately half of the urban population resided in small and mediumsized cities in the 1990s. Although many smaller cities began to grow and upgrade their status from Small to Medium or Large, the number of smaller cities and their population remain excessively large, thus distorting the structure of China's urban system. In comparison to other countries, the linear relationship between the natural logarithm of the city rank and size in China is not as apparent, due to the long curved tail which represents small cities (Graph 6). However, as shown in Graph 6, if the small cities (cities with population less than 20,000 , which are represented by the dots below the $\ln (20,000)$ line in the diagram) in China were excluded from the examination of the rank-size relationship, a remarkable log-linear pattern would emerge. Therefore, the overabundance of small cities has resulted in the imbalance of city size distribution.

The development of small cities is inevitable in China's urbanisation processes, since it is traditionally an agricultural country with a massive rural population. There is a surplus rural population of 200 million and such an enormous amount of excess labour has created an overwhelming demand for employment that cannot be met by large cities alone. (21) Small cities, as well as towns, act as a link between rural and urban life by transporting technology, culture, and economic benefits to rural areas, thus helping to coordinate a more balanced development. (22) However, the development of too many small cities would inevitably lead to a series of socioeconomic problems. For instance, small cities are less efficient in terms of the production of goods: they produce less while consuming more energy than large cities. Small cities' ability to absorb surplus rural labour declines more quickly over time than a large city, until it eventually reaches a saturated state when it can no longer offer economic benefits to new rural migrants. ${ }^{(23)}$ Additionally, lack of economic advantages makes it difficult for small cities to attract investment and consequently increase in size. Small cities are generally distributed sparsely over space without fully functional infrastructure and management systems. A common issue that can be observed in most small cities is the waste of land due to the lack of urban planning and administration. (24)

What has caused this structural distortion of China's urban system? Aside from the fact that China is an agricultural country with the largest population in the world, the government's urban policies have also been a major contributing factor. Since the 1980s, China's urban development policy has been continually encouraging the growth of small cities, which has resulted in many undersized cities and significantly distorted the citysize distribution ratio. In giving small cities and towns priority for the allocation of financial resources, the government has facilitated the development of TVEs and increased the number of established towns. Fortunately, in recognition of the uneven nature of China's urbanisation, the central government has suspended the designation of new cities as of 1997. As indicated in Graph 2, the number of county-level cities even began to decline after 1997 due to the fact that some small and middle-

20. The Rank-Size Distribution diagram is drawn following these steps: 1) Take the largest city in a country and give it the ranking number 1 ; take the second largest and give it the ranking number 2 ; keep on doing this for the remaining cities, or possibly selecting cities exceeding a certain size. 2) Calculate the natural logarithm of the rank and of the city size (population) and plot the resulting data in a diagram, and then a log-linear pattern can be drawn.

21. Huhua Cao, Ying Zhao, and Sylvain Losier, art.cit.

22. Huhua Cao, Omer Chouinard, and Olivier Dehoorne, "De la périphérie vers le centre: l'évolution de l'espace francophone du Nouveau Brunswick au Canada" (from the Periphery to the Centre: Evolution of the French-Speaking Community in New Brunswick in Canada), Annales de Géographie, Vol. 642, 2005, pp. 115-140

23. Lamia Kamal-Chaoui, Edward Leman, and Rufei Zhang, "Urban Trends and Policy in China," op. cit. 24. Shunfeng Song and Kevin Honglin Zhang, "Urbanisation and City Size Distribution in China," art. cit. 

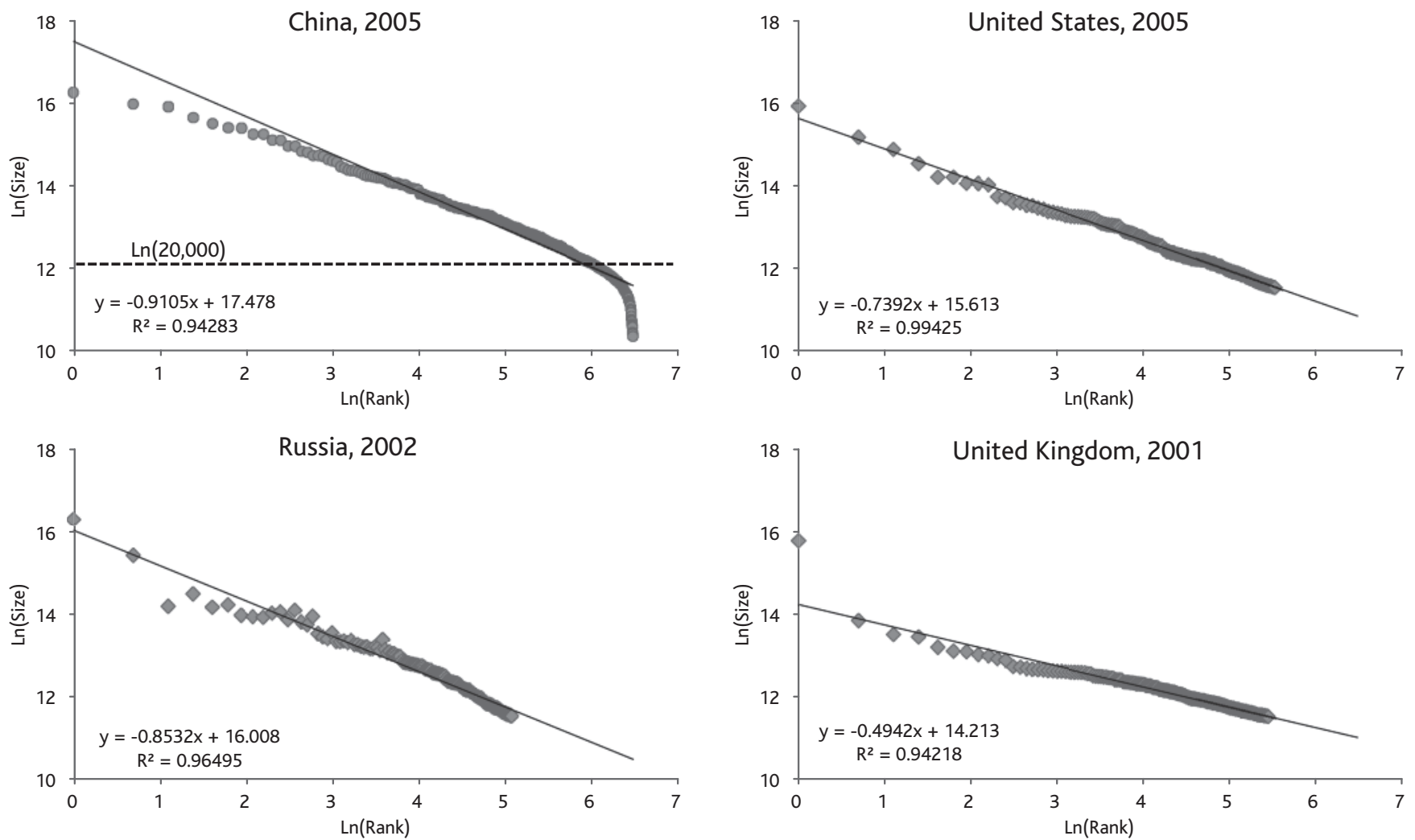

Data source: China City Statistical Yearbook 2006; U.S. Census Bureau, www.census.gov; All-Russia Population Census of 2002, Federal State Statistics Service, 2004; The UK's major urban areas, Office for National Statistics, 2001.

sized cities either evolved into large cities themselves, or agglomerated with nearby large cities to form districts.

\section{Emergence of urban clusters}

Although the number of cities in China remains stable, they have continued to expand in size due to rural-urban migration over the last decade. Due to increased mobility within the urban system, connections between cities have been established and reinforced: large cities attract the flow of material, capital, and labour and play a leading role within the region. As a result of the formation of these connections, urban clusters or city strips dominated by metropolitan cities have gradually taken shape.

Using remote sensing images to present real observations of urban development has a long established history. ${ }^{(25)}$ Instead of using imagery captured by traditional sensors during the day, this study selected images that were collected at night by the Defence Meteorological Satellite Program's Operational Linescan System (DMSP OLS). In comparison to Geographic Information Systems (GIS)-based methods such as interpolation, population dots, or urban density, the night-time light images have a greater ability to depict urban areas in terms of their density and boundaries. Consequently, DMSP OLS images are often used to depict the extent of urban settlement in a specific area. (26) Using a thresholding technique, (27) the stable lights data sets of 1995 and 2006 were selected and processed for examining urban cluster development, and the resulting patterns are mapped in Map 2. The dark areas on the map represent large urban cores and the colour becomes lighter in more remote areas since the nightlight illumination diminishes with the increasing distance from the urban core.

Urban clusters in China are usually found in the plains, deltas, and industrial districts. ${ }^{(28)}$ The comparison of maps in Map 2 demonstrates the emergence of major urban clusters between 1995 and 2005 as detailed below.

\section{Northeast urban strip (Harbin-Shenyang-Dalian):}

This cluster has been the national centre for heavy industry since the 1950s. This region spreads from Harbin in the north to Dalian in the

25. James R. Anderson, Ernest E. Hardy, John T. Roach, and Richard E. Witmer, "A Land Use and Land Cover Classification System for Use with Remote Sensor Data," Geological survey professional paper 964, Washington, United States Government Printing Office, 1976; and Steve N. Gillanders, Nicholas C. Coops, Michael A. Wulder, and Nicholas R. Goodwin, "Application of Landsat Satellite Imagery to Monitor Land-Cover Changes at the Athabasca Oil Sands, Alberta, Canada," Canadian Geographer, Vol. 52, No. 4, 2008, pp. 466-485.

26. Christopher D. Elvidge, Marc L. Imhoff, Kimberly E. Baugh, Vinita Ruth Hobson, Ingrid Nelson, Jeff Safran, John B. Dietz, and Benjamin T. Tuttle, "Night-Time Lights of the World: 1994-1995," ISPRS Journal of Photogrammetry and Remote Sensing, Vol. 56, No. 2, 2001, pp. 81-99; Shenjing He, Zhigang Li, and Fulong Wu, "Transformation of the Chinese City, 1995-2005: Geographical Perspectives and Geographers' Contributions," China Information, Vol. 20, No. 3, 2006, pp. 429-456; M. Henderson, E.T.Yeh, P. Gong, C. Elvidge, and K. Baugh, "Validation of Urban Boundaries Derived from Clobal Night-Time Satellite Imagery," International Journal of Remote Sensing, Vol. 24, No. 3, 2003, pp. 595-610.

27. Marc L.Imhoff, William T. Lawrence, David C. Stutzer, and Christopher D. Elvidge, "A Technique for Using Composite DMSP/OLS 'City Lights' Satellite Data to Map Urban Area," Remote Sensing of Environment, Vol. 61, No. 3, 1997, pp. 361-370; C. P. Lo, "Modeling the Population of China Using DMSP Operational Linescan System Nighttime Data," Photogrammetric Engineering and Remote Sensing, Vol. 67, No. 9, 2001, pp. 1037-1047.

28. Anthony Gar-On Yeh and Xueqiang Xu, "Urbanisation and Urban System Development in China," op. cit. 


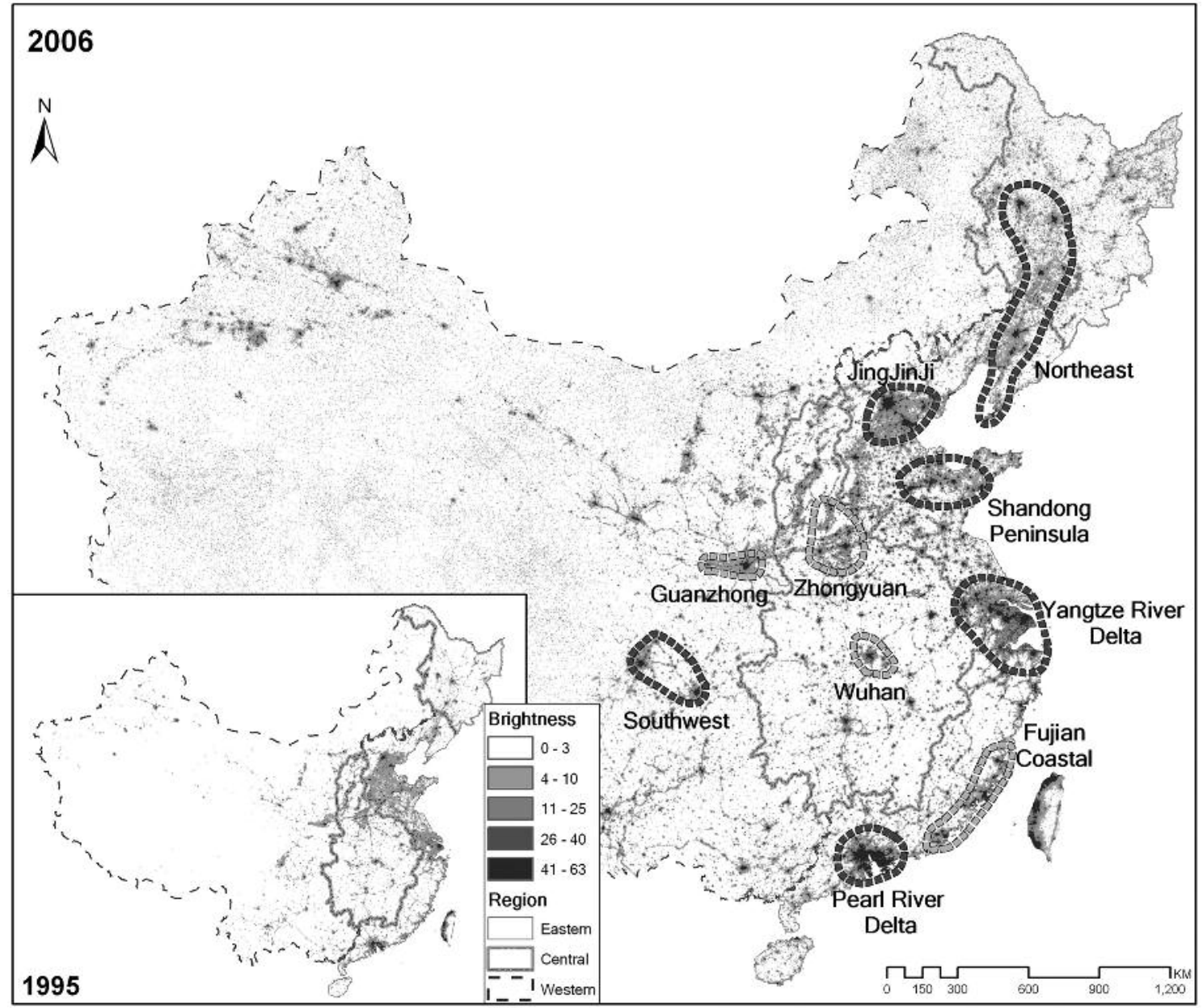

Data source: DMSP Operational Linescan System (OLS), www.ngdc.noaa.gov/dmsp/

south, and the transportation is featured by a "one vertical, three horizontal" network that connect three capital cities, Harbin, Shenyang, and Dalian, from north to south and link regional cities to these capital cities. Cities in the region include Changchun, Jilin, Anshan, Fushun, Benxi, and Liaoyang. Although this urban cluster has been facing challenges in maintaining economic dynamics due to the exhaustion of natural resources, industrial restructuring and rehabilitation since the 1990s have reinforced its position as the fourth economic pillar of China.

\section{JingJinJi urban cluster (Beijing-Tianjin-Tangshan):}

The jinglinji urban cluster has evolved in a hub-spoke pattern. Beijing and Tianjin are the dominant cities in this cluster, working as nodes at the top hierarchy. The highly developed railway/highway network connects second-tier cities of this region including Tangshan, Shijia- zhuang, Baoding, Qinhuangdao, Langfang, Cangzhou, Chengde, and Zhangjiakou.

\section{Shandong Peninsula urban cluster:}

Due to its abundance of agricultural, forestry, and fishery products and its proximity to Korea and Japan, Shandong Peninsula has experienced rapid development since the implementation of economic reforms. The Shandong Peninsula urban cluster has been formed with the industrial development of electronic information, equipment manufacturing, and new materials, representing a new industrial cluster and growth pole along the eastern coast. This newly developed cluster is dominated by jinan and Qingdao, and Yantai is the major port in the region.

\section{Yangtze River Delta (YRD) urban cluster (Nanjing- Shanghai-Hangzhou):}

As one of the most robust and dynamic urban clusters in China, The Yangtze River Delta urban cluster is dominated by Shanghai, with Nanjing and Hangzhou acting as supporting cities. Other notable cities within the cluster include Wuxi, Suzhou, Changzhou, Ningbo, and Nantong. The Nanjing-Shanghai-Hangzhou-Ningbo railway, the Grand Canal, and the Yangtze River connect these cities to one another by facilitating travel and communication.

\section{Pearl River Delta urban cluster:}

The group of cities surrounding Hong Kong, from Shenzhen and Guangzhou in the north to Macao and Zhuhai in the west, form the Pearl River Delta urban cluster. This cluster, which includes six major cities in Guangdong Province (Foshan, Jiangmen, Huizhou, Zhaoging, Dongguan, and Zhongshan), is becoming a megalopolis of inter-locking hubs with varying policies related to investment, migration, business, and political freedom. 


\section{Southwest urban cluster:}

This is the largest urban cluster in Western China and it features a dualcore structure. The dominant cities, Chongqing and Chengdu, are strong enough to function as major growth poles. Other important cities within this cluster include Zigong, Luzhou, Deyang, Mianyang, Suining, Neijiang, Leshan, Nanchong, Meishan, Yibin, Guang'an, Ya'an, and Ziyang.

Based on the information provided by the DMSP OLS imagery, new urban clusters have also been identified, which include: the Fujian Coastal urban cluster (\#7 on Map 2), the Wuhan urban cluster (\#8), the Zhongyuan urban cluster (\#9), the Guanzhong urban cluster (\#10), and the Xinjiang urban cluster (\#11), most of which are still in the preliminary stages of development. The majority of these 11 clusters are situated either in deltas or on plains that have abundant natural resources and a long history of development. Furthermore, they have high population density and are known for different agricultural or industrial production specialties. Since they are located along the coast or important transportation lines and are more accessible to the world market, the economic reform and open policy period has been beneficial to their growth and prosperity. In addition to the in creasing development of existing cities, new cities are beginning to emerge in established urban clusters. For example, Dongguan, Shenzhen, and Zhuhai are gaining importance in the Pearl River Delta, and Changzhou continues to expand in the Yangtze River Delta. ${ }^{29}$

\section{Challenges facing the structure of China's urban system}

\section{Inconsistent definition of cities and towns, and urban population}

The status of a city has practical importance for its own development and its residents: once an urban place is recognised as a designated city, it is entitled to a greater allotment of financial resources and its residents gain access to better public facilities and social services. However, the criteria for city and town designation and official urban population definition have changed frequently since the 1950s, making the data and statistics concerning urban studies inconsistent and difficult to compare longitudinally. Chen ${ }^{(30)}$ and Liu et al. (31) summarised the history of the definition of cities and towns in detail.

Early official criteria from the 1950s to the 1970s for the designation of cities and towns were based on an urban region's population and administrative status. (32) More specifically, areas with a clustered population of more than 100,000 were designated as cities, and those with a population of less than 100,000 could obtain the city designation if they met certain requirements such as industry or mining. These criteria were altered based on the proportion of non-agricultural population when a need to increase or decrease the number of cities was required by the central government for economic reasons, as cities were sustained by the later. Since the mid1980s, Gross National Product (GNP) was included in the definition system. The current definition of cities and towns was adopted in 1993, and the scale of the non-agricultural population remains the most important factor for China when designating cities. Various requirements in the minimum size of non-agricultural population, GDP, the share of the tertiary industry, local financial revenues, and level of urban infrastructure were specified, making the definition system extremely complicated and confusing. (33)
Unfortunately, the official definition of the urban population is also frequently changing, making it increasingly difficult to accurately assess China's urban population and urbanisation level. According to Ma and Cui, Chinese authorities such as the State Council Population Census Office, Ministry of Public Security, and the National Bureau of Statistics published eight types of official statistical data relating to the urban population. ${ }^{(34)}$ The figure generated by Zhuoyong Chen ${ }^{(35)}$ (reproduced in Graph 7) clearly depicts the discrepancy among the four most frequently used types of data.

The statistics on urban populations have consistently been adjusted according to the national censuses of 1953, 1964, 1982, 1990, and 2000. For example, a city/town population based on the 1982 census definition includes all of the population residing in designated cities and towns, which includes both the non-agricultural population and agricultural population. However, this data cannot be used to reflect the urbanisation process, because those agricultural populations are not really urbanized as they don't have access to urban services. Instead, non-agricultural population refers to the urban population according to the household registration system, and is not influenced by the fluctuating categorization of cities. Therefore, nonagricultural population is preferred by some academics since it is consistent and comparable along temporal and spatial scales. However, it is often criticised for its underestimation of the rapid growth of population, since it does not include migrant workers and rural-urban migrants who do not have an urban household registration. ${ }^{(36)}$

The changing definitions of cities and towns and population censuses have a significant impact on the reported number of cities and towns. A complicated definition system also makes it difficult to accurately examine the development speed, since it is obscured by the quantity of urban areas. Furthermore, the primary sources for official statistics on China's urbanisation have caused confusion and misunderstanding due to their lack of consistency.

\section{Identifying and managing the role of urban clusters}

Since the mid-1990s, China's urbanisation has been characterised by the fact that large cities are the principal sources of urbanisation, and as a result more urban clusters are emerging across the country. ${ }^{(37)}$ Recognising this reality, the central government has begun to gradually alter its urbanisation plan to encourage the expansion of large cities. In 2001, the Tenth Five-Year Plan was promulgated to conceive a "coordinated development of large, medium, small cities and small towns" while focusing on the development of large cities. ${ }^{(38)}$

29. Shunfeng Song and Kevin Honglin Zhang, "Urbanisation and City Size Distribution in China," art. cit:; Anthony Gar-On Yeh and Xuegiang Xu, "Urbanisation and Urban System Development in China," op. cit.; Simon X.B. Zhao, Roger C.K. Chan, and Kelvin T.O. Sit, "Globalization and the Dominance of Large Cities in Contemporary China," Cities, Vol. 20, No. 4, 2003, pp. 265-278; Yanting Zheng, Tian Chen, Jianming Cai, and Shenghe Liu, "Regional Concentration and RegionBased Urban Transition: China's Mega-Urban Region Formation in the 1990s," Urban Geography, Vol. 30, No. 3, 2009, pp. 312-333.

30. Zhuoyong Chen, "Urbanisation and Spatial Structure Evolution of Urban System in China," op. cit.

31. Shenghe Liu, Xiubin Li, and Ming Zhang, "Scenario Analysis on Urbanisation and Rural-Urban Migration in China," Institute of Geographic Sciences and Natural resources Research, Beijing, Chinese Academy of Sciences, 2003

32 Ibid.

33. Ibid.

34. J.C. Ma Laurence and Gonghao Cui, "Administrative Changes and Urban Population in China," Annals of the Association of American Geographers, Vol. 77, No. 3, 1987, pp. 373-395.

35. Zhuoyong Chen, "Urbanisation and Spatial Structure Evolution of Urban System in China,"op. cit.

36. Litao Zhao and Jianying Li,"China Reforming the Hukou System: Reducing Discrimination against the Rural Population," EAI Background Brief No. 284, 2006.

37. Zhuoyong Chen, "Urbanisation and Spatial Structure Evolution of Urban System in China,"op. cit.

38. Lamia Kamal-Chaoui, Edward Leman, and Rufei Zhang, "Urban Trends and Policy in China," op. cit. 


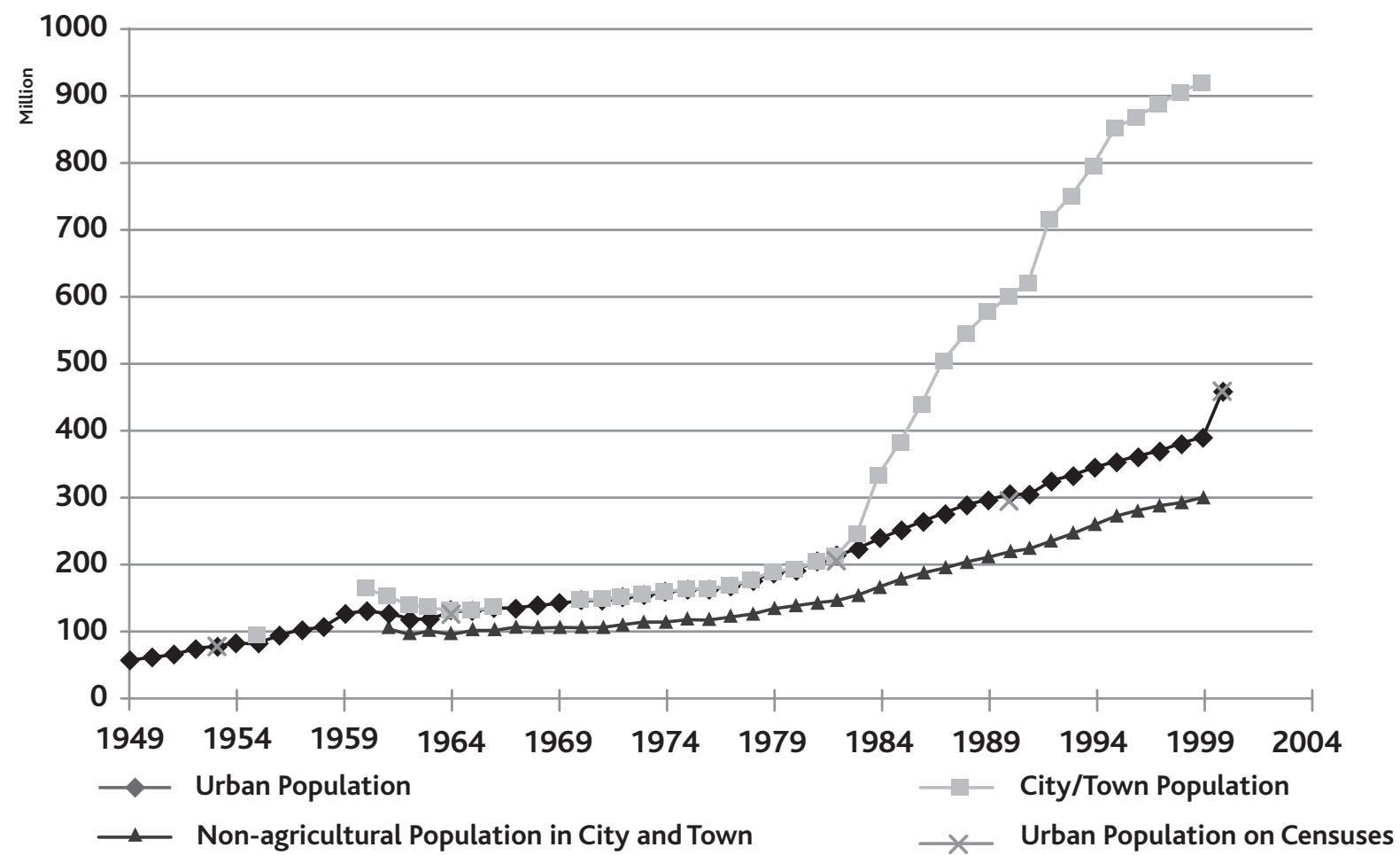

Urban population refers to the population that live in designated cities, City/Town Population includes population that live in both Cities and Towns, Non-Agricultural Population in Cities and Towns refers only to those residents that have urban hukou, Urban Population on Census are populations compted as urban in the China Census.

Source: Zhuoyong Chen, "Urbanisation and Spatial Structure Evolution of Urban System in China," IDE-JETRO, 2008, www.ide.go.jp/English/Publish/Download/Vrf/pdf/439.pdf (accessed on 26

The $11^{\text {th }}$ Five-Year Plan, launched in 2006, explicitly stated that "making megalopolises the leader, exercising the functions of central cities and forming several new megalopolises with less land utilization, more employments, and rational population distribution" was China's top priority (39).

In this context, it becomes crucial to properly plan the growth of urban clusters and maximise their leading role in strengthening rural-urban linkages. Since China lacks experience in developing metropolises, it is extremely challenging to plan for their growth. Most of the current urban clusters are in their preliminary stages, and incorporated cities usually share physical or economic links. China also lacks a comprehensive system or plan to coordinate the development of its cities. For example, the jinglinji urban cluster is one of the earliest metropolises, and Beijing and Tianjin are the dominant cities of this region. Due to its political status as the capital city of China, Beijing's development has always received precedence, and a relationship of domination has slowly replaced its once collaborative relationship with Tianjin and other surrounding cities. Ultimately, the development of Tianjin has been impeded by the "shadow effect" of Beijing.

To effectively utilise urban clusters as a viable catalyst for urban development, the barriers to the implementation of this strategy must be mitigated. First, efforts should be made to create a comprehensive development strategy that integrates all cities of an urban cluster. This is challenging to put into practice because local municipalities in each cluster still depend on internal revenue allotments from the central government and continue to make development plans independently. To change the status quo, the central government and local authorities will have to involve themselves in the cluster's policies, plans, and programs in order to design economic policies and coordinate economic resources.
Secondly, urban sector programs should be considered in a cluster's development strategy. The leading city in an urban cluster is usually comprehensive in its economic makeup, with a robust tertiary industry, and subordinate cities should identify with a specific service that it can uniquely provide. For example, by taking into consideration the advantages and disadvantages of various types of cities, some can be targeted for heavy industry, some for logistics, and some for tourism and recreation. Ideally, the integrated development of city clusters would use urban infrastructure and services as the skeleton, and economic and social relationships as the lifeblood to achieve a sustainable level of development. ${ }^{(40)}$ Specific policies such as special economic zones, industrial parks, and other development enclaves should be properly employed in pursuing additional opportunities and attracting external investment.

\section{Spatial transition}

China's urban system has not only experienced a structural transition, but also a significant spatial transition with regard to the distribution of cities and urban development patterns.

\section{Transitional patterns}

Centrographic Analysis is a spatial statistics tool that can be used to track the growth of cities while monitoring their movement. More specifically,

39. Ibid.

40. K. Choe and A. Laquian, City Cluster Development: Toward an Urban-Led Development Strategy for Asia, Mandaluyong City, Philippines: Asian Development Bank, 2008 




Population threshold of each category: 0.1-0.2 million for a small city, 0.2-0.5 million for a medium city, $0.5-1$ million for a large city, 1-2 million for an extra-large city, and >2 million for a metropolitan city. Data source: China City Statistical Yearbook 1986, 1996, 2006

this tool creates standard deviational ellipses to summarise the spatial characteristics of geographic features. A common way of measuring the development trend for cities is to record the geographic centre (or the centre concentration) of cities using GIS methods, which can be used to reveal movement patterns. For example, if the centre of the ellipse has moved, that means the development of cities has shifted; if the area has increased, that means the urban development has been dispersed. The statistics can give useful insights into the central tendency, dispersion, and directional movement patterns of Chinese cities. By examining the location, size and the rotations of the ellipses, the Centrographic Analysis tool allows users to examine if the distribution of cities in China is elongated or rotated, and hence has a particular pattern of orientation. ${ }^{(41)}$

The standard deviation ellipses in Map 3 demonstrate the spatial expansion and movement tendencies of Chinese cities in the past two decades. Compared to the ellipse of 1985 , that of 1995 moved to the southeast, rotated counterclockwise and shrank. In other words, the cities along the southeast coast were growing much faster than cities in other regions of China, pulling the centre of development to the southeast. From 1995 to 2005, the ellipse moved south and its cover area expanded, meaning that cities in the south were expanding relatively faster, drawing the gravity of urban development in that direction. As indicated on the map for small cities in Map 3, small cities were more widely scattered, but were becoming concentrated after 1995. Since 1985, mediumsized cities in central and western China have been growing notably. After 1995, large and extra-large cities in the south were expanding at an exceptional rate to pull the ellipse south by a considerable distance (Map 3).

\section{Challenges of eliminating spatial disparity and inequality}

In China, there is a great disparity between the development of cities in the west and the development of cities in the east. ${ }^{(42)}$ For example, in the

41. Huhua Cao and Ying Zhao, "The Application of Centrographic Analysis to the Study of the IntraUrban Migratory Phenomenon in the Greater Moncton Area in Canada, 1981-1996," Romanian Review on Political Geography, Vol. 1, 2003, pp. 16-25. 
Table 2 - Chinese cities by region in 1985, 1995, and 2005

\begin{tabular}{|c|c|c|c|c|c|c|}
\hline \multirow{2}{*}{ Region } & \multicolumn{2}{|c|}{1985} & \multicolumn{2}{|c|}{1995} & \multicolumn{2}{|c|}{2005} \\
\hline & Number of cities & Pop (Million) & Number of cities & Pop (Million) & Number of cities & Pop (Million) \\
\hline East & 102 & 56.32 & 273 & 99.61 & 263 & 161.13 \\
\hline Centre & 117 & 36.68 & 215 & 62.71 & 227 & 84.22 \\
\hline West & 105 & 25.26 & 152 & 37.84 & 171 & 54.67 \\
\hline Total & 324 & 118.25 & 640 & 200.16 & 661 & 300.02 \\
\hline
\end{tabular}

The cities referred to here have a population of 100,000 inhabitants or more. Data source:The Compilation of 50 Years' Urban Statistics of New China; The Compilation of the Demographic Statistics of China 1949-1985; China City Statistical Yearbook 2001, 2006; China Population and Employment Statistics Yearbook 2008

mid-1980s the ratio of the number of cities in the eastern, central, and western regions was 1:1.15:1.03 (102:117:105 in absolute numbers, Table 2). By 2005 , the rapid development of eastern cities shifted the ratio to 1:0.86:0.65 (Table 2). In spite of increased urbanisation, the inequality between the coastal and inland areas is continuing to grow in all aspects.

China's entry into the World Trade Organization (WTO) in 2001 brought about the prospect of international trade and communication. Economic prosperity is concentrated in large coastal cities due to their better access to international investment and world markets, and their urban development has accelerated economic progress. ${ }^{(43)}$ In addition, the trickle-down effect of these large cities' success stimulates the development of small cities surrounding them, which is usually a significant contribution in the early stages of urbanisation. However, most of the large cities (83\%), with an urban population over 5 million, are located in the eastern and central regions, whereas the western region only contains a small number of large cities. Moreover, large inland cities are lagging behind large coastal cities, which possess high human capital and relatively good consumer amenities. ${ }^{(44)}$

Since the inland areas are already at a disadvantage in terms of geographic location, access to resources, and the quality and quantity of human capital, it is extremely challenging to narrow the socio-economic gap between urban development in the east and that in the west. Urban development policies, plans, and programs in both regions should be given equal importance to minimize inequities and growth imbalances. Special measures should be devised to prevent the marginalisation of inland areas in economic and social activities by giving them access to, and control over, economic resources. The opening of new SEZs served as a good example:Tacheng, Bole, and Yining in Xinjiang were opened as SEZs in 1992 to promote the economic links to Central Asia (Map 1). In addition, the urban policy-making process for each city should take into consideration its position in the urban hierarchy (systems of cities) and geographic advantages, so that a specifically tailored plan can be implemented to meet its urbanisation challenges. ${ }^{(45)}$

\section{Conclusion}

As this research has demonstrated, Chinese cities have witnessed significant transformation in terms of their institutional and spatial structures. The transition of Chinese cities into participants in the global market reflects the urban transition process of the developing world. ${ }^{(46)}$ The urbanisation experience of other developed and developing countries can also help to direct China's future urbanisation. For instance, international experience indicates that manufacturing is often concentrated in metropolises as economic development begins, then diffuses to other cities, and eventually leads to increased specialisation and division of labour between small and large urban centres. ${ }^{(47)}$ China's economic prosperity relies heavily on the manufacturing industry, and consequently large coastal cities have a disproportionate concentration of manufacturing companies as opposed to financial services. This indicates that China is still in the early stages of industrialisation and economic development, and will therefore undergo substantial structural changes in the near future as its development progresses.

China's urban growth is a substantial achievement that has attracted the world's attention. However, in addition to the challenges of its institutional "enigma," imbalanced structure, and spatial inequality, the socioeconomic gap between the urban and rural populations has continued to widen. To reduce this discrepancy the Chinese government will have to adopt certain reforms, such as social security and welfare reform, and ensure that the proportions of rural and urban investment are equalised through increased rural investment. Despite the fact that China's cities are expanding by encroaching on agricultural land, they are not yet fully prepared for the massive influx of rural migrants that comes with urbanisation. The high speed of urban construction without proper planning and administration has caused a series of recurring urban issues such as traffic congestion, lack of affordable housing and social infrastructure, environmental degradation, and an overall decline in the quality of life. How to confront these challenges while maintaining its fast pace of urbanisation has become one of the most difficult challenges for China's urban planning administration. To effectively address the issues of economic and environmental sustainability, joint efforts between the central government and willing parties are required in order to devise and maintain healthy management mechanisms, production techniques, and an infrastructure development scheme.

I Han Ruibo is a Post-doctoral Fellow at the Department of Geography, University of Ottawa. 60 University Private, Ottawa, Ontario, Canada K1N 6N5 (hanruibo@hotmail.com).

I Wang Linna is a Masters' Candidate, Department of Economics, University of Ottawa. 120 University Private, Ottawa, Ontario, Canada K1N 6N5 (ln@live.ca).

42. H. Cao, and S. Bergeron, Disparités régionales et inclusion des minorités: les défis de la Chine de l'après Jeux Olympiques de Beijing (Regional Disparity and Minority Inclusion: The Challenges of China after Beijing 2008 Olympic Games), Québec, Presses de l'Université du Québec, 2010.

43. K. Choe and A. Laquian, City Cluster Development: Toward an Urban-Led Development Strategy for Asia, op. cit

44. Somik Lall and Hyoung Gun Wang, "China Urbanisation Review: Balancing Urban Transformation and Spatial Inclusion," The World Bank, 2010.

45. Ibid.

46. Weiping Wu, "Migrant Settlement and Spatial Transformation in Urban China: The Case of Shanghai," World Bank Third Urban Research Symposium, Brasilia, Brazil, 2005

47. Somik Lall and Hyoung Gun Wang, "China Urbanisation Review: Balancing Urban Transformation and Spatial Inclusion," op. cit. 